\title{
Assessment of Moisture Permeability and Closure Systems of High Density Polyethylene Plastic Bottles Used as Primary Packaging Containers for Moisture Sensitive Medicines
}

\author{
Raphael Shedafa1,2, Prosper Tibalinda², Vicky Manyanga1,3, Joseph Sempombe1, \\ Marry Temu ${ }^{3}$, Nelson Masota ${ }^{1}$, Eliangiringa Kaale ${ }^{1,3}$, Christoph Bonsmann ${ }^{4}$ \\ ${ }^{1}$ Medicinal Chemistry Department, Muhimbili University of Health and Allied Sciences (MUHAS), Dar-es-Salaam, \\ Tanzania \\ ${ }^{2}$ Pharm R\&D Laboratory, School of Pharmacy, Muhimbili University of Health and Allied Sciences (MUHAS), \\ Dar-es-Salaam, Tanzania \\ ${ }^{3}$ Department of Pharmaceutics and Pharmacy Practice, Muhimbili University of Health and Allied Sciences \\ (MUHAS), Dar-es-Salaam, Tanzania \\ ${ }^{4}$ German Medical Aid Organization, Tonisvorst, Germany \\ Email: raphael.shedafa@gmail.com
}

Received 18 April 2016; accepted 8 August 2016; published 11 August 2016

Copyright (C) 2016 by authors and Scientific Research Publishing Inc.

This work is licensed under the Creative Commons Attribution International License (CC BY).

http://creativecommons.org/licenses/by/4.0/

(c) (i) Open Access

\section{Abstract}

Introduction: Moisture permeability and a loose closure system might allow a significant gain of moisture into container and this could lead to significant loss of potency of drug sensitive to moisture and as well promoting the growth of microorganisms. Typical examples of the drugs sensitive to moisture include Tenofovir Disoproxil Fumarate (TDF). Product claimed to be a "Tight container" does not make it a tight container until proved practically. A plastic container is tight if "not more than one of the 10 tested containers exceeds $100 \mathrm{mg}$ per day per $\mathrm{L}$ in moisture permeability. Objectives: The goal of this study was to determine rate of moisture permeability of selected High Density Polyethylene plastic bottles for packaging of moisture sensitive medicines in particular Lamivudine/Tenofovir Disoproxil fumarate tablets. Methodology: The determination of rate of moisture permeability was achieved by assessing closure systems of plastics as per USP $37<671>$ method, while the difference in absorption pattern was achieved by assessing the spectrum obtained through transmittance by Fourier Transform-Infrared (FT-IR). The plastic bottles were randomly selected from supplier A, B and C. Results: The plastic bottles from supplier A and B had 
an average moisture permeability of 12.57 and $51.55 \mathrm{mg} / \mathrm{day} / \mathrm{L}$ with none of the containers exceeding moisture permeability of $100 \mathrm{mg} / \mathrm{day} / \mathrm{L}$ whereas containers from supplier $\mathrm{C}$ had an average of $149.95 \mathrm{mg} /$ day/L with seven of the containers exceeding of $100 \mathrm{mg} / \mathrm{day} / \mathrm{L}$. Conclusion: Containers from supplier A and B met the USP specifications hence could be used as primary packaging for moisture sensitive medicines whereas the containers from supplier C did not meet the USP specifications for them to be regarded as "Tight Containers" and hence, unsuitable for packaging of moisture sensitive medicines.

\section{Keywords}

Moisture, Permeability, Closure System, Primary Packaging Containers

\section{Introduction}

The packaging process of a pharmaceutical product is aimed at making sure that the quality of the finished product is preserved and hence the drug product of acceptable quality gets to the end user. Hence, packaging should preserve stability and quality of medicinal products and protects them against all forms of spoilage and tampering [1].

High density polyethylene bottles are used in a variety of applications and industries where excellent impact resistance, high tensile strength, low moisture absorption and chemical and corrosion resistance properties are required [2].

For pharmaceutical solid oral dosage forms, it is well recognized that the most common cause for a packaged product failing to meet its specification is its instability, as a result of "moisture uptake" [3]. The failure is usually related to out-of-specification or out-of-range values in any or combination of the following quality attributes: assay, product degradants, dissolution rate, and other physical properties [4]. Pharmaceutical solid oral dosage forms are typically packaged in plastic bottles, thermoformed plastic blisters, or cold-formed aluminum blisters. These container closure systems are sealed either by compression-fit between a hard surface and a soft surface or by application of heat to an adhesive layer of polymers [5]. They are considered semi-permeable packages and therefore the moisture barrier properties need to be characterized [6].

All pharmaceutical products have to be packaged in containers that adhere to the prescribed pharmacopoeial standards particularly for solid dosage forms moisture appears to be critical as compared to other dosage forms such as liquids [7]. This indicates the need for a routine post-marketing surveillance to check whether the packaging materials of the products on the market suit the environment in which the product is to be accessed by the end users [8].

\section{Procedure}

\subsection{Sample Preparation}

Containers from different suppliers named A, B and C and different batches (12 unit each) were selected for moisture permeation test where 2 containers where used as controls [9].

All the containers were stored at $75 \% \pm 3 \%$ relative humidity and a temperature of $23 \pm 2$ degrees in humidity climatic chamber for 14 days [10] [11].

\subsection{Material}

The sample containers were collected from different suppliers and coded as supplier A, B and C. Calcium chloride (4 - 8 mesh) as desiccant and sodium chloride-RANKEM (RFCL), Okhla industrial area, New Delhi (INDIA) were used for moisture determination.

\subsection{Sample Analysis}

\subsubsection{Tested Parameters}

Two parameters were determined in this study, these includes, identifications and moisture permeability of the 
High density polyethylene plastic bottles.

\subsubsection{Moisture Permeation}

The sample containers were subjected to humidity controlled chamber at $75 \% \pm 3 \%$ relative humidity and a temperature of $23^{\circ} \mathrm{C} \pm 2^{\circ} \mathrm{C}$ for 14 days, later moisture uptake was determined for each container.

\subsubsection{Fourier-Transform Infrared}

The transmittance of the plastic was determined by Fourier Transform Infrared (FT-IR).

\section{Results and Discussion}

It can be seen in the results indicated in Figure 1, containers supplied by supplier C were incorrectly regarded as "Tight containers" as their average rate of moisture permeability was not within the range specified in the USP $37<671>$ whereas containers supplied by supplier A and B were correctly regarded as "Tight containers" as their average rate of moisture permeability values were within the range specified in the USP Pharmacopeia.

All of these spectra in the region above $1500(>1500)$ are comparable to the HDPE reference spectrum in Figure 2. In the fingerprint region to the right-hand side of the diagram in Figure 2 (from about 1500 to 500 $\mathrm{cm}^{-1}$ ) the reference HDPE spectrum is different from the spectra for container A, B and C. These are mainly due to all manner of bending vibrations within the molecule. The importance of the fingerprint region is that each different compound produces a different pattern of troughs in this part of the spectrum.

This indicates the fact that the reference HDPE is different from the HDPE containers collected from the market. It can be observed in Figure 2, spectra of plastic container from supplier A and C over-laid together with the reference HDPE spectrum show a remarkable absorption pattern difference indicating the plausible differences in chemical composition; however, this difference is largely pronounced in infra-red spectrum of HDPE containers from supplier C. This could explain as to why the HDPE containers from supplier C were failing the moisture permeability test.

\section{Conclusions}

It is of public interest to test the integrity of the container closure systems as it was found in this study that there were some medicinal containers on the market which were claimed to be "Tight containers" whereas practically found not to be the case. From the three Suppliers of containers tested in this study, two suppliers (A and B) met the USP Pharmacopoeia specifications and the containers were correctly regarded as "Tight containers" while one, supplier C did not, and the containers were regarded as "Not Tight" (Figure 1). Hence, containers from sup-

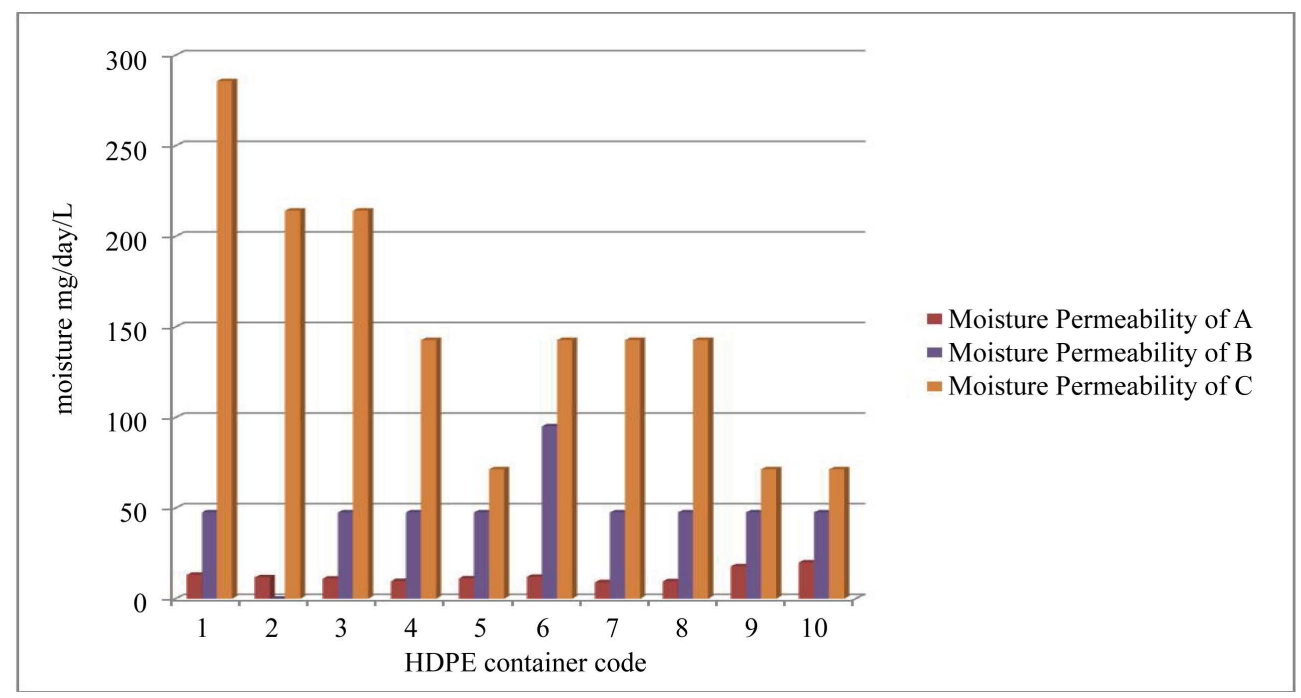

Figure 1. A bar chart of rate of moisture permeability for ten tested containers from different suppliers i.e coded supplier A, B and C. 


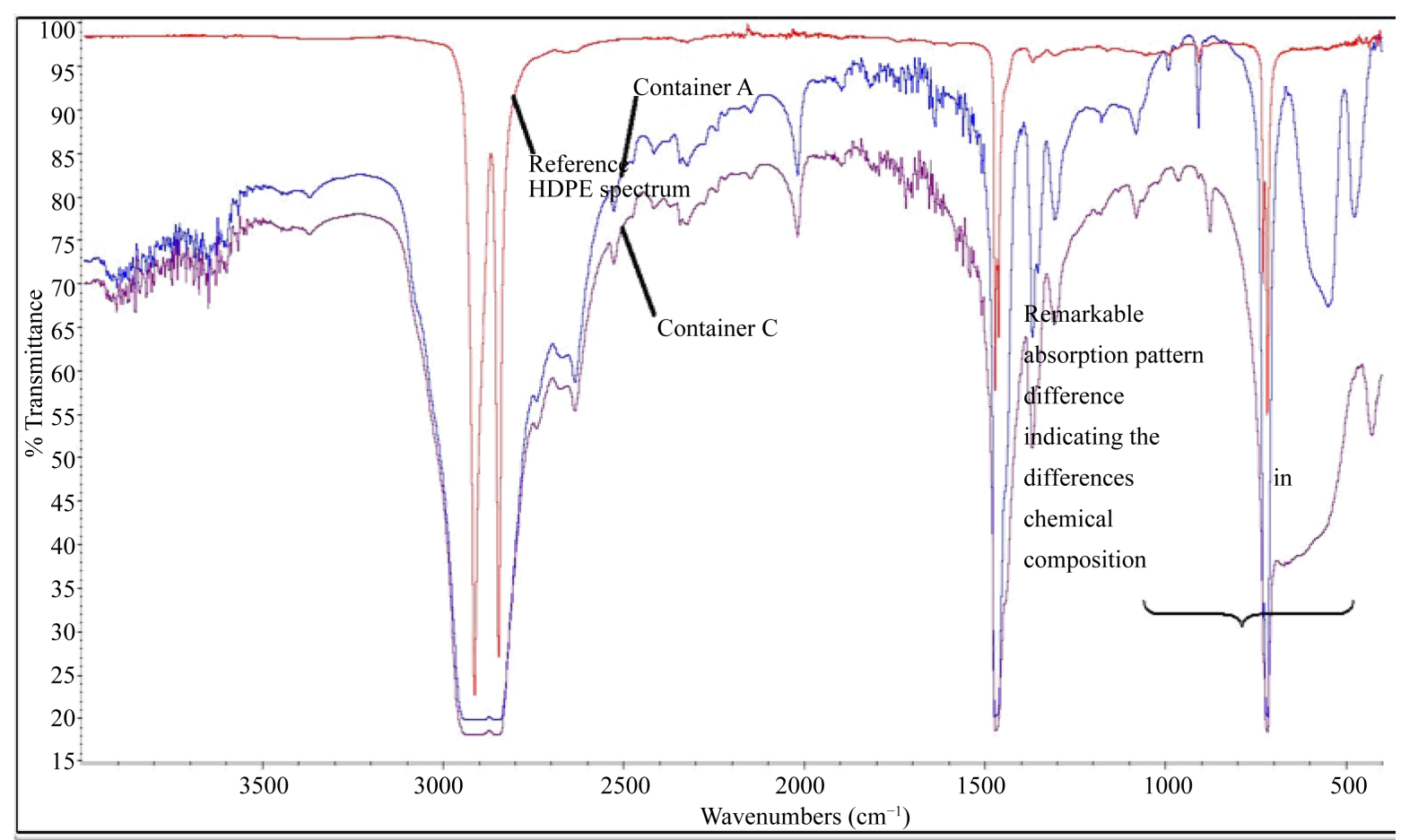

Figure 2. Spectra of plastic container from supplier A and C over-laid together with the reference HDPE spectrum, all scanned from $4000-400 \mathrm{~cm}^{-1}$ with $\mathrm{KBr}$ as a detector and a total of 16 scans were collected.

plier A and B can be used as primary packaging containers for Lamivudine and Tenofovir Disoproxil Fumarate (TDF) Fixed Dose combination (FDC) as since Tenofovir Disoproxil Fumarate can be hydrolysed in the presence of moisture and hence regarded as a moisture sensitive drug which has to be packed in "Tight containers".

It was generally found that the volume of the container had no effect on the results, as to whether regarding a container Tight or Not Tight since the Tight containers' volume ranged from smallest ( $80 \mathrm{~mL})$ to the largest being $150 \mathrm{~mL}$.

From the infra-red spectra of HDPE bottles as compared to the reference HDPE spectrum it can be concluded that the infra-red spectrum of the container failing on closure system study does not differ significantly from the container passing on the same study and from the reference spectrum. This indicates clearly that failing on moisture permeability is not associated with the quality of material used but rather the integrity of the closure system.

\section{Acknowledgements}

We appreciate the support from action medeor, Tanzania and Germany,SIDA and MUHAS for financial support by providing the reagents and materials for the study. Also we acknowledge the technical contribution from members of staff of Pharmaceutical Research and Development Laboratory (Pharm R\&D) Laboratory, MUHAS; Ms. Ruth Ng'wananogu and Ms. Bertha Francis, Mr. Edson Lutta and Mr. Mhando Maro.

\section{References}

[1] Veronin, M. (2011) Packaging and Labeling of Pharmaceutical Products Obtained from the Internet. Journal of Medical Internet Research, 13. http://dx.doi.org/10.2196/jmir.1441

[2] Declarations, E.P. and Manufacturers, E.P. High Density Polyethylene (HDPE), (n.d.).

[3] Fda, C. (1999) Cder, Container Closure Systems for Packaging Human Drugs and Biologics, Guid. Ind.

[4] Woods, E.J., Bagchi, A., Goebel, W.S., Vilivalam, V.D. and Vilivalam, V.D. (2010) Container System for Enabling Commercial Production of Cryopreserved Cell Therapy Products. Regenerative Medicine, 5, 659-667. http://dx.doi.org/10.2217/rme.10.41

[5] Yoon, S., Sparks, D. and Selke, S. (2009) A Discussion of Net Water Gain for Water Vapor Transmission Rate Deter- 
minations. Phamacopoeial Forum, 35, 488-492.

[6] Chen, Y. and Li, Y. (2008) Determination of Water Vapor Transmission Rate (WVTR) of HDPE Bottles for Pharmaceutical Products. International Journal of Pharmaceutics, 358, 137-143. http://dx.doi.org/10.1016/j.ijpharm.2008.02.031

[7] Waterman, K.C. and MacDonald, B.C. (2010) Package Selection for Moisture Protection for Solid, Oral Drug Products. Journal of Pharmaceutical Sciences, 99, 4437-4452. http://dx.doi.org/10.1002/jps.22161

[8] Packaging, F. and Issues, E. (2007) Food Packaging-Roles, Materials, and Environmental Issues. Journal of Food Science, 72, R39-R55. http://dx.doi.org/10.1111/j.1750-3841.2007.00301.x

[9] Requirements, S., Containers, S., Containers, S., Transmission, L., Notices, G. and Transmission, L. <671> Containers-Performance Testing, i (n.d.).

[10] (2009) Annex 2 Stability Testing of Active Pharmaceutical Ingredients and Finished Pharmaceutical Products. 87-130.

[11] Thomas, M.S. (2010) Pharmaceutical Packaging Development.

\section{Submit or recommend next manuscript to SCIRP and we will provide best service for you:}

Accepting pre-submission inquiries through Email, Facebook, LinkedIn, Twitter, etc.

A wide selection of journals (inclusive of 9 subjects, more than 200 journals)

Providing 24-hour high-quality service

User-friendly online submission system

Fair and swift peer-review system

Efficient typesetting and proofreading procedure

Display of the result of downloads and visits, as well as the number of cited articles

Maximum dissemination of your research work

Submit your manuscript at: http://papersubmission.scirp.org/ 